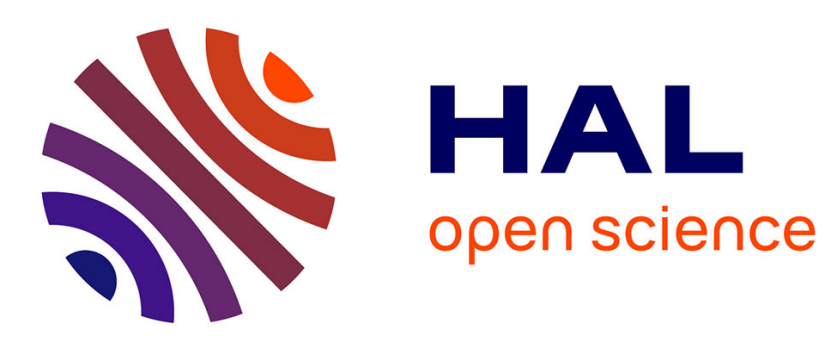

\title{
Precipitation kinetics in N18 P/M superalloy: experimental study and numerical modelling
}

\author{
N. Gayraud, F. Moret, X. Baillin, P. Mosser
}

\section{To cite this version:}

N. Gayraud, F. Moret, X. Baillin, P. Mosser. Precipitation kinetics in N18 P/M superalloy: experimental study and numerical modelling. Journal de Physique IV Proceedings, 1993, 03 (C7), pp.C7-271-C7-276. 10.1051/jp4:1993743 . jpa-00252161

\section{HAL Id: jpa-00252161 https://hal.science/jpa-00252161}

Submitted on 1 Jan 1993

HAL is a multi-disciplinary open access archive for the deposit and dissemination of scientific research documents, whether they are published or not. The documents may come from teaching and research institutions in France or abroad, or from public or private research centers.
L'archive ouverte pluridisciplinaire HAL, est destinée au dépôt et à la diffusion de documents scientifiques de niveau recherche, publiés ou non, émanant des établissements d'enseignement et de recherche français ou étrangers, des laboratoires publics ou privés. 


\title{
Precipitation kinetics in N18 P/M superalloy: experimental study and numerical modelling
}

\author{
N. GAYRAUD, F. MORET, X. BAILLIN and P.E. MOSSER* \\ CEREM/Laboratoire de Génie des Matériaux, CENG - 85X, 38041 Grenoble cedex, France \\ * SNECMA, 291 av. d'Argenteuil, 92230 Gennevilliers, France
}

\begin{abstract}
Heat treatments of aeronautical turbine disks produced by powder metallurgy include $\gamma^{\prime}$ solutionning, quenching and subsequent annealing. In the present work, the intragranular $\gamma^{\prime}$ precipitation kinetics during the quench has been followed by dilatometry and transmission electron microscopy. The precipitation steps are studied on specimens "hyperquenched" from selected temperatures during a simulated industrial quench. Experimental results are compared with a pseudo-binary model based on classical homogeneous nucleation and coarsening theories. While the precipitate volume fraction is lower than $20 \%$, a good quantitative agreement is observed.
\end{abstract}

\section{INTRODUCTION}

The excellent high temperature strength of the superalloys used in aeronautical gas turbines is derived from the precipitation of ordered and coherent $\gamma^{\prime}$ phase $\mathrm{Ni}_{3}(\mathrm{Al}, \mathrm{Ti})$ within $\mathrm{Ni}$ solid solution. The mechanical properties of these materials are strongly dependent upon the microstructure produced during thermal treatments. This work is focussed on the experimental study and the modelling of intragranular $\gamma^{\prime}$ precipitation (also called secondary precipitation) during the oil quench corresponding to a $200 \mathrm{~K} / \mathrm{min}(3 \mathrm{~K} / \mathrm{s})$ quench rate.

A previous experimental study has been discussed in [1]. Further work is done to improve the comparison with the model, through the evaluation of volume fraction (from dilatometry experiments) and the determination of the precipitate size by TEM (from dilatometry and high quench rate experiments). The alloy we study is the N18, a complex commercial grade used by SNECMA for turbine disks [2].

The characterization of the $\gamma \rightarrow \gamma+\gamma^{\prime}$ transformation through dilatometric experiments and TEM has also been published by HAZOTTE and SIMON but on the single crystal superalloy CMSX-2 [3].

\section{EXPERIMENTAL}

All the experiments have been performed with material from the same atomized, extruded and isothermally forged bar of $\mathrm{N} 18(\mathrm{Ni}-15.5 \mathrm{Co}-11.4 \mathrm{Cr}-4.3 \mathrm{Al}-4.3 \mathrm{Ti}-6.4 \mathrm{Mo} \mathrm{wt} \%)$. In the fabrication standard, the material is solution treated at $1165^{\circ} \mathrm{C}$ during 4 hours, then quenched, which provides the precipitation of fine intragranular $\gamma^{\prime}$ precipitates, and finally, is submitted to annealing in order to stabilize the structure by coarsening of intragranular $\gamma^{\prime}$ precipitates. At room temperature, the volume fraction of $\gamma^{\prime}$ phase reaches $55 \%$. The heat treatment was performed in the radiation furnace of the dilatometer: the specimens were heated at $50 \mathrm{~K} / \mathrm{s}$ prior to annealing for 4 hours. The subsequent cooling was forced by helium. Calculated temperature homogeneity in the diameter of $\mathrm{N} 18$ dilatometry specimens were $0.5 \mathrm{~K}$ for $3 \mathrm{~K} / \mathrm{s}(180 \mathrm{~K} / \mathrm{mn})$, the typical cooling rate, and $23 \mathrm{~K}$ for $170 \mathrm{~K} / \mathrm{s}(10200 \mathrm{~K} / \mathrm{mn})$, the highest used cooling rate. A special "hyperquenching" 
furnace has been used to study the different steps of the precipitation and is described elsewhere [4]. Dilatometric specimens were then studied by Transmission Electron Microscopy (TEM). Dilatometric and microscopic experimental techniques have been fully described in [1]. The foils were observed in dark field mode using the $[100]$ superlattice reflexion.

\section{EXPERIMENTAL RESULTS}

\section{Dilatometry}

As described in [1], dilatometry experiments have been conducted in order to follow the evolution of the $\gamma^{\prime}$ volume fraction during quenching. Figure 1 illustrates a typical dilatometric record obtained at $3 \mathrm{~K} / \mathrm{s}$ (180 $\mathrm{K} / \mathrm{mn}$ ). After the thermal transient, a quasi linear contraction is observed followed by a sudden slope change around $1130^{\circ} \mathrm{C}$. This sudden contraction is related to the precipitation phenomenon. Then, a continuous contraction with a small positive curvature is observed down to room temperature. This experiment is in good agreement with the modelling. An undercooling is necessary to enable massive nucleation, which occurs $35 \mathrm{~K}$ under the equilibrium temperature.

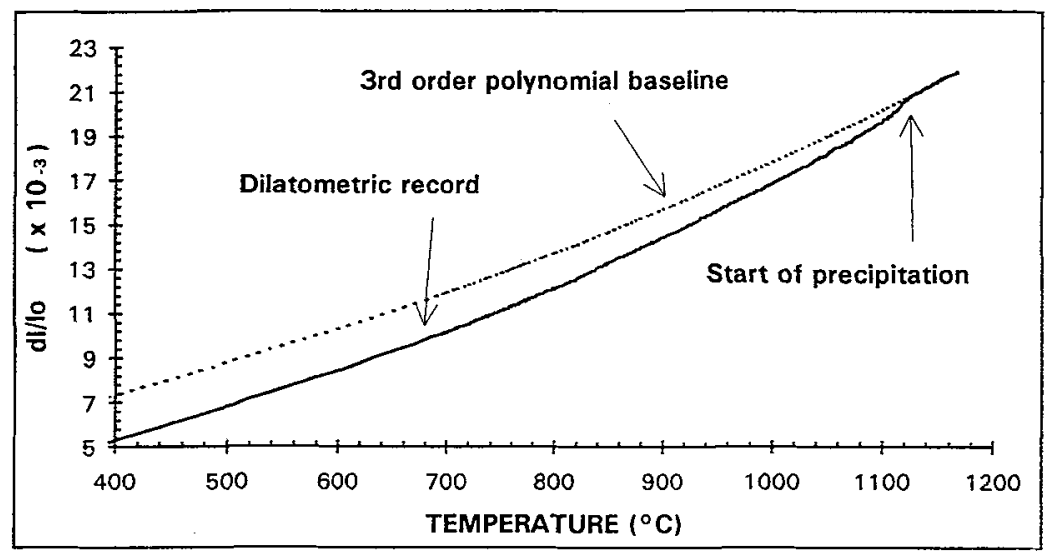

Fig.1: Dilatometric curve obtained for a cooling rate of $3 \mathrm{~K} / \mathrm{s}(180 \mathrm{~K} / \mathrm{mn})$ from the solution treatment at $1165^{\circ} \mathrm{C}$ in $\mathrm{N} 18$.

A more sophisticated method than the one described in [1] has been used to analyse the precipitation kinetics from the dilatometric curves. Assuming that the dilatation of the material results from the contribution of both volume fraction and expansion coefficient, we use a $3^{\text {rd }}$ order polynomial absolute baseline (Fig.1) which is representative of the expansion coefficient of $\gamma$ and $\gamma^{\prime}$ phases. The polynomial baseline derivative is interpolated from the portions of the curve non submitted to phase transformation, that is between room temperature and $600^{\circ} \mathrm{C}$ (due to the low diffusion coefficient) and the slope above $1130^{\circ} \mathrm{C}$ (before the beginning of the secondary precipitation). The absolute ordinate position of the baseline is fitted with the experimental curve at $1140^{\circ} \mathrm{C}$. The so called treated curve is obtained by substracting the experimental curve to the interpolated one.

Fig.2 presents an example of two experiments submitted to the same cooling rate, $3 \mathrm{~K} / \mathrm{s}$, and showing the reproductibility of the dilatometric results. As the thermal expansion coefficients of $\gamma$ and $\gamma^{\prime}$ phases are close (see for example [5]), a more sophisticated baseline correction including CTE mismatch between the two phases did not seem reasonable compared with other experimental uncertainties. In the following, it is assumed that the treated dilatometric curve is proportionnal to the precipitated volume fraction. Effects linking this curve with the actual precipitated volume fraction are complex, largely not quantified (elastic stresses, vacancies) and will not be discussed henceforth, but a linear relation seems plausible [6].

Dilatometry experiments were used to study the effect of cooling rate on precipitation kinetics and 7 cooling rates ranging from 0.8 to $170 \mathrm{~K} / \mathrm{s}$ (20 to $10200 \mathrm{~K} / \mathrm{mn}$ ) have been performed. After a numerical filtering, some of the treated dilatometric records are plotted on Fig.3.

It has already been shown in [1] that the temperature of the inflexion point (maximum of the derivative) 
decreases as the cooling rate increases with an approximate slope of $10 \mathrm{~K}$ per decade of the cooling rate, in agreement with known thermodynamic and kinetic parameters.

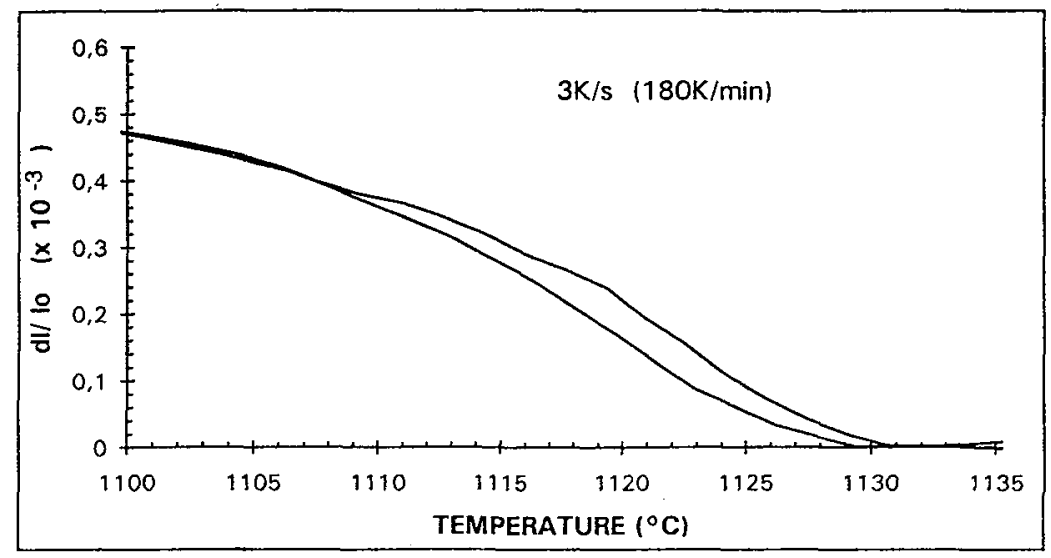

Fig.2: Treated dilatometric curves of two specimens for a cooling rates of $3 \mathrm{~K} / \mathrm{s}(180 \mathrm{~K} / \mathrm{min})$ from the $1165^{\circ} \mathrm{C}$ solution temperature (reproductibility test).

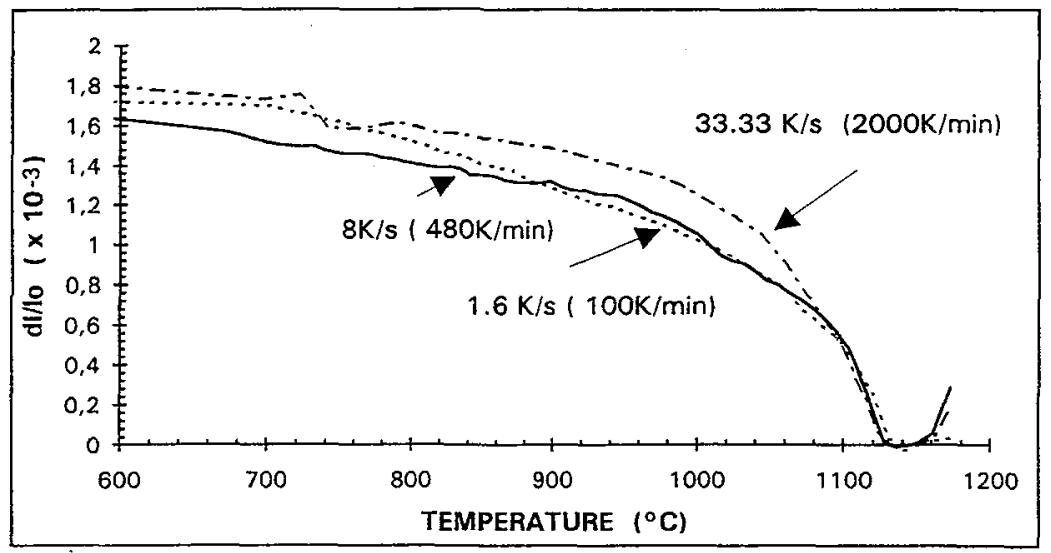

Fig.3: Treated dilatometric curves showing, the volume fraction of intragranular precipitation for cooling rates of $1.66 \mathrm{~K} / \mathrm{s}(100 \mathrm{~K} / \mathrm{min}), 8 \mathrm{~K} / \mathrm{s}(480 \mathrm{~K} / \mathrm{min})$ and $33.33 \mathrm{~K} / \mathrm{s}(2000 \mathrm{~K} / \mathrm{min})$ from the $1165^{\circ} \mathrm{C}$ solution temperature.

\section{Microstructures}

The microstructures of the samples cooled continuously down to room temperature are presented in [1]. The size of the secondary $\gamma^{\prime}$ precipitates decreases with the cooling rate and their morphology moves from spheres for small precipitates to octocuboïdal and butterfly shapes (due to anisothermal conditions [7] )for large particules.

In order to follow step by step the phenomenon of the first stages of the precipitation, we developed a high quench rate apparatus described in [4]. The microstructure of five specimens submitted to a sudden $10^{4-5} \mathrm{~K} / \mathrm{s}$ quench at selected temperatures during a $3 \mathrm{~K} / \mathrm{s}$ quench (known within an accuracy of $\pm 2^{\circ} \mathrm{C}$ ) are reported in Fig. 4. Due to the "hyperquench" rate, only a few $3 \mathrm{~nm}$ intragranular precipitates are observed on Fig 5-a. Small clusters of about $0.5 \mathrm{~nm}$ in diameter were also observed (maybe related to fluctuations of the solid solution short range order). Fig 5-b shows that a high density of small precipitates has formed at $1123^{\circ} \mathrm{C}$. 

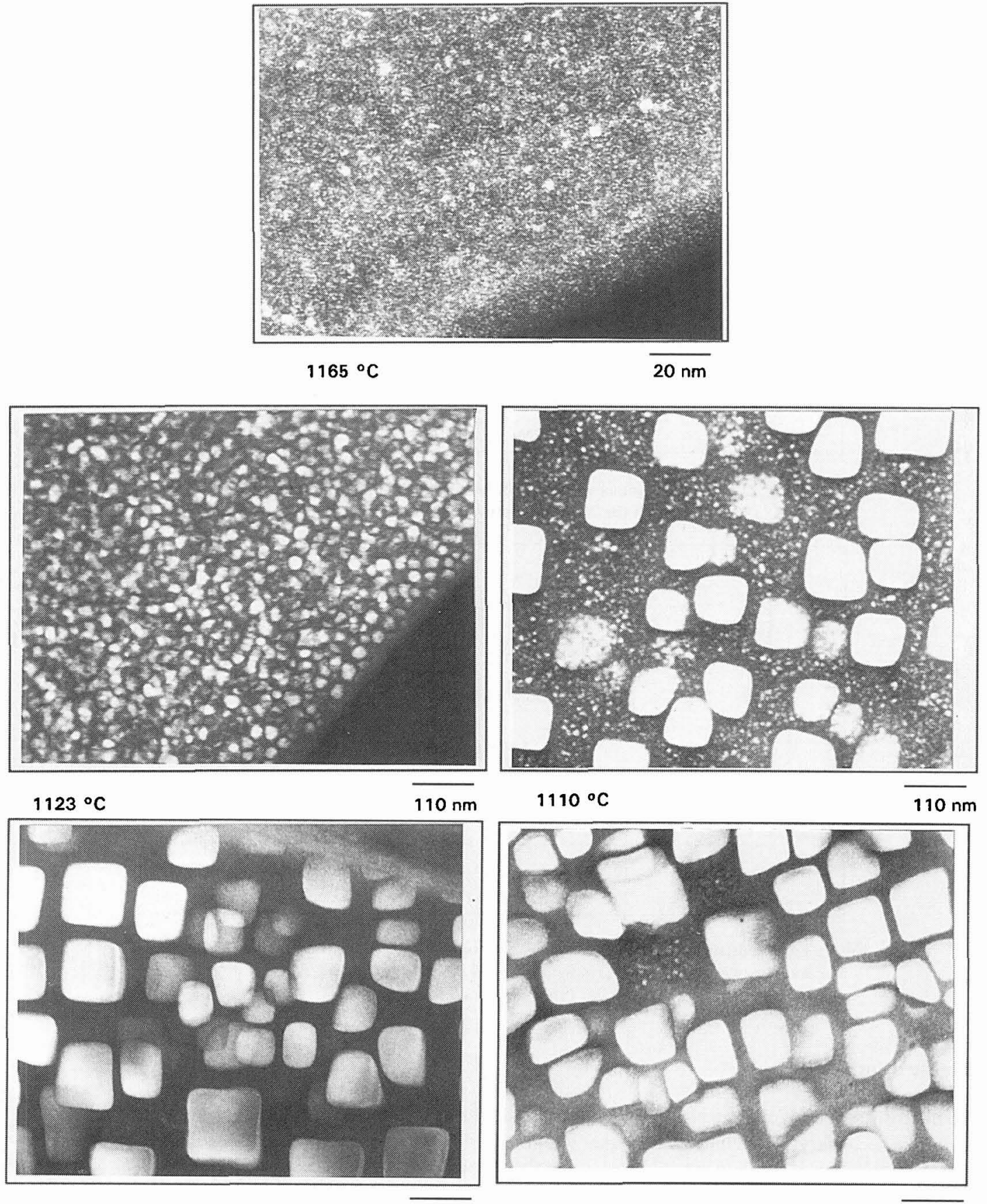

$1020^{\circ} \mathrm{C}$

$110 \mathrm{~nm}$

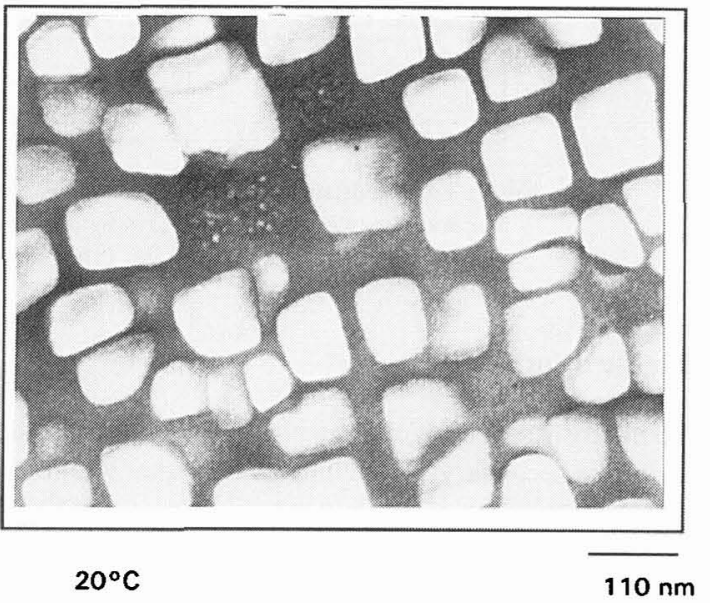

Fig.4 Dark field TEM observations of the specimens hyperquenched (a) from the solution temperature, $1165^{\circ} \mathrm{C}$, from (b) $1123^{\circ} \mathrm{C}$, (c) $1110^{\circ} \mathrm{C}$, (d) $1020^{\circ} \mathrm{C}$ during a $3 \mathrm{~K} / \mathrm{s}$ quench and (e) of the sample quenched down to room temperature.

At this stage a high nucleation rate event already occurred, providing $15 \mathrm{~nm}$ spherical particules. As the temperature decreases down to $1110^{\circ} \mathrm{C}$, the precipitates start to coarsen up to $90-130 \mathrm{~nm}$ in size and consequently they move to cuboïdal shape (Fig.5-c). The coarsening process of the precipitates is still taking 
place at $1020^{\circ} \mathrm{C}$ (Fig.5-d) and their size is observed between 120 and $140 \mathrm{~nm}$. The precipitate size remains almost unchanged down to room temperature (Fig.5-e).

\section{COMPARISON BETWEEN MODELLING AND EXPERIMENTAL RESULTS}

The precipitation phenomenon is described by classical nucleation and coarsening equations presented in [1], assuming a mean diffusionnal field (LSW hypothesis). Recent experimental studies of the first steps of nucleation and coarsening of $\gamma^{\prime}$ precipitates in binary $\mathrm{Ni}-\mathrm{Al}$ and a simplified $\mathrm{Ni}-\mathrm{Co}-\mathrm{Cr}-\mathrm{Al}-\mathrm{Ti}$ alloy [8-9-10] at moderate temperatures $\left(550-650^{\circ} \mathrm{C}\right)$ have shown that such equations are relevant. The numerical model calculates the evolution of the whole precipitate size density for each time step of the thermal history of the specimen.

\section{Dilatometry}

The evolution of the calculated volume fraction with temperature given by the modelling, is plotted in figure 6 for the cooling rate of $3 \mathrm{~K} / \mathrm{s}$. This curve predicts three distinct precipitations.

As the volume fraction scale is unknown for the experimental curve, it is fitted by two points to the calculated curve (at the temperature of start of nucleation and at the temperature of the end of secondary precipitation). The experimental and calculated curves are in good agreement above $950^{\circ} \mathrm{C}$ but do not have the same evolution at lower temperatures. The model allows a good description of the kinetics of the secondary precipitation but is not relevant at temperatures lower than $950^{\circ} \mathrm{C}$ (and volume fraction higher than $20 \%$ ), probably due to strong diffusionnal interactions between the precipitates not taken into account by the equations. This discontinuous behaviour could disagree with ARDELL's conclusion [11] concerning the invariance of $\gamma^{\prime}$ coarsening kinetics over a wide range of volume fractions. In our anisothermal case, we observe that diffusionnal interactions inhibit new nucleation phenomenon, independently of the coarsening behaviour.

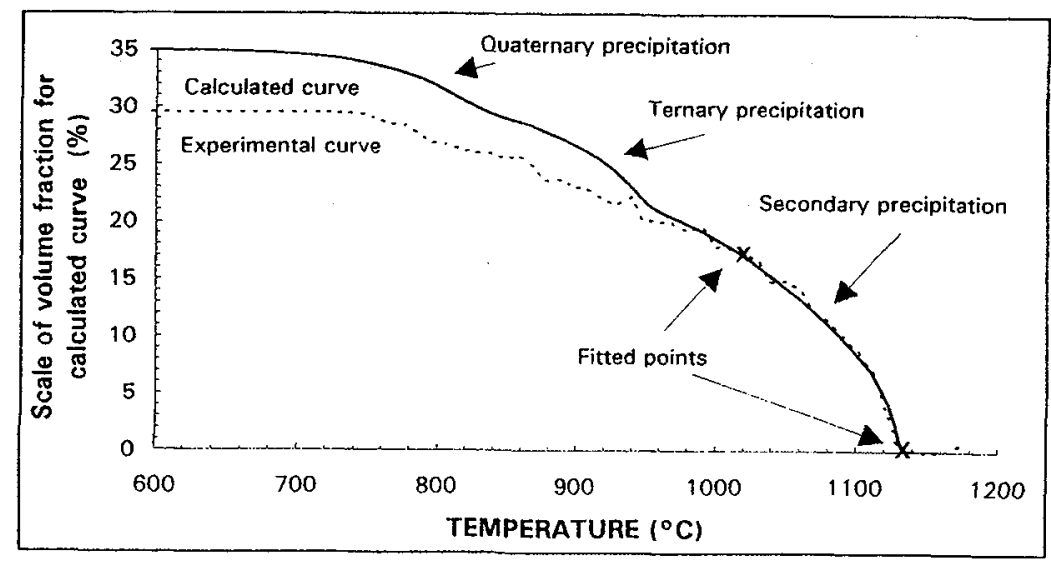

Fig. 5 Evolution of calculated and experimental volume fraction with temperature The experimental curve is fitted by two points to the calculated results

\section{High temperature microstructure}

Fig. 6 displays the evolution of the size and density of the precipitates obtained from the model and from the microstructural observation, over the quench temperatures. The calculated size is in agreement with the experimental result for temperatures ranging from $1123^{\circ} \mathrm{C}$ to room temperature. A reasonable description of the density of the precipitates below $1110^{\circ} \mathrm{C}$ is also given by the calculation with only one order of magnitude 
difference between both results. On the other hand, the model is in disagreement concerning the very first stages of the precipitation.

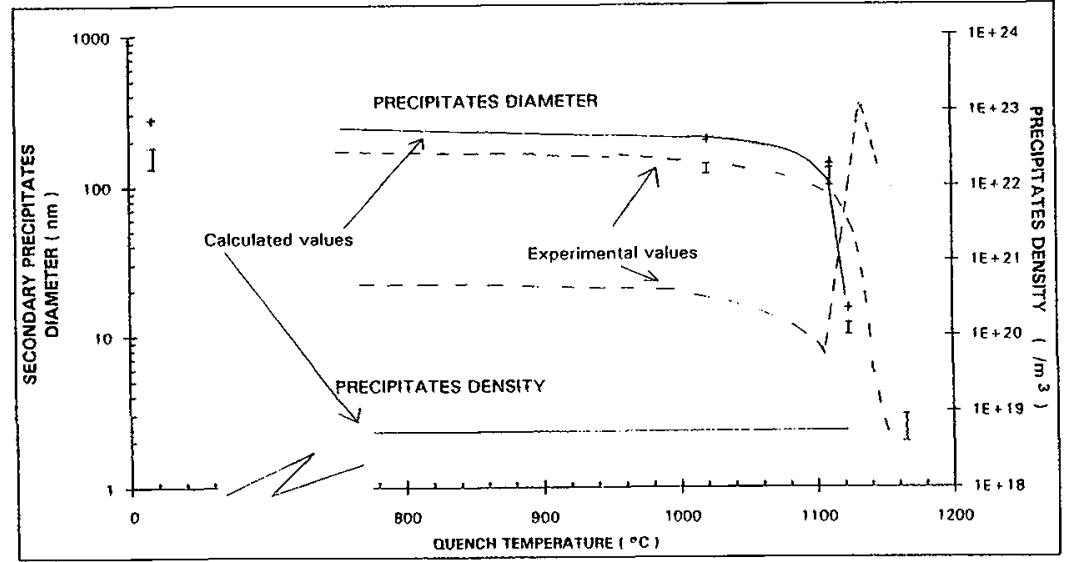

Fig.6 Experimental and calculated size and density of precipitates as a function of quench temperature

\section{CONCLUSION}

Initial steps of $\gamma^{\prime}$ precipitation during the industrial quench of $P / M N 18$ superalloy have been studied by dilatometer and TEM of "hyperquenched" specimens at selected temperatures.

A good qualitative agreement is observed between experimental results and a numerical model based on classical nucleation and coarsening theories from the solution temperature to $950^{\circ} \mathrm{C}$, i.e. for the volume fractions below $20 \%$. At lower temperatures (higher volume fractions), diffusionnal interactions between the precipitates strongly modifies the kinetics.

Further modelling work should be based on Monte Carlo atomistic simulations described for instance by ABINANDANAN [12]. As the communicating neighbours concept introduced by DE HOFF [13] assumes the lack of solute source except precipitates, it cannot be applied in the non-isothermal coarsening case studied here.

\section{ACKNOWLEDGEMENTS}

The authors acknowledge Dr. A.ALAMO and Dr. J.C. BRACHET (CEREM/ Saclay) for their help in the dilatometric experiments, Dr I.ANSARA and G.MARTIN (CEREM/ Saclay) for useful discussions. This work is partially supported by Ministère de l'Enseignement Supérieur et de la Recherche.

\section{REFERENCES}

[1] GAYRAUD N., MORET. F., MOSSER, P.E., EUROMAT conf., Gênes, 22-24 sept (1992)

[2] DUCROCQ C., LASALMONIE A., HONNORAT Y. Superalloys, TMS, (1988), 63

[3] HAZOTTE A., SIMON A., First ASM Europe Tech. Conf., T.Khan, A.Lasalmonie, Paris, 7 sept (1987), 83

[4] GAYRAUD N., MORET F., DESBOIS P., BAILLIN X., This conference

[5] "Thermophysical properties of matter", IFI:PLENUM, 12, 225 (1977)

[6] GROSDIDIER T., thesis, I.N.P. Lorraine, 7 Jul. (1992)

[7] MÜLLER L., GLATZEL U., FELLER-KNIEPMEIER M., Acta. Metall. Mater., 40, N6, 132 (1992)

[8] WENDT H., HAASEN P., Acta. Met., 30,1561-1570 (1982)

[9] CHAMBRELAND S., BLAVETTE D., Acta. Met., 36, 12, 3205-3215, (1988)

[10] XIAO X.et HAASEN P. Acta. Met. Mater., 39 (1991)

[11] ARDELL A.J., Scripta. Metall. Mater., 24, 343 (1990)

[12] ABINANDANAN T., MARTIN G., Internal Report, CEREM Saclay (1992)

[13] DE HOFF R.T., Acta. Metall. Mater., 39, 10,2349 (1991) 